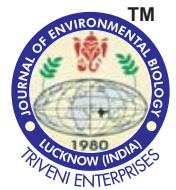

\title{
Oxidative stress and cholinesterase depression among farm workers occupationally exposed to pesticides in India
}

ISSN: 0254-8704 (Print)

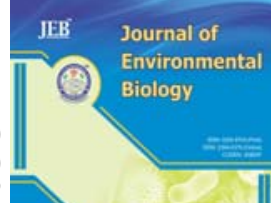

\section{Authors Info \\ M. Fareed ${ }^{12 *}$, C.N. Kesavachandran', V. Bihari', R. Kamal ${ }^{1}$ and M. Kuddus ${ }^{3}$ \\ ${ }^{1}$ Epidemiology Division, CSIR - Indian Institute of Toxicology Research, Lucknow-226 001, India \\ ${ }^{2}$ Department of Public Health, College of Medicine, Al Imam Muhammad Ibn Saud Islamic University, Riyadh-13317-4233, Kingdom of Saudi Arabia \\ ${ }^{3}$ Department of Biochemistry, College of Medicine, University of Hail, Hail, 81451, Kingdom of Saudi Arabia \\ *Corresponding Author Email : fareed.research@gmail.com}

Key words

Cholinesterase depression, Occupational exposure, Oxidative stress,

Pesticides

\section{Publication Info}

Paper received : 16.10 .2015

Revised received : 16.05.2016

Re-revised received : 25.07.2016

Accepted : 20.09.2016

\section{Abstract}

Aim: This study aims to investigate the oxidative stress and cholinesterase levels among agricultural workers occupationally exposed to various agricultural pesticides.

Methodology: Across sectional study was performed among fifty two male pesticide sprayers of Lucknow district in India, compared with thirty control subjects. Pesticide sprayers were selected on the basis of clinical examination for acute and chronic health symptoms associated with pesticide exposure.

Results: Clinical examination of pesticide sprayers showed significant health problems $(p<0.05)$ for different organ systems. Activities of acetylcholinesterase and butyrylcholinesterase were significantly depressed $(p<0.05)$ among pesticide sprayers as compared to controls showing the exposure to pesticides among them. Activity of blood CAT was higher but not statistically significant; activity of blood GPx was significantly higher $(p<0.05)$; blood GSH was significantly decreased $(p<0.05)$; blood MDA level was more in pesticide sprayers as compared to control subjects, but not statistically significant. These results show the sub-clinical state of oxidative stress among pesticide sprayers.

Interpretation: The present study showed that occupational exposure to pesticides leads to cholinesterase depression and alterations in anti-oxidant enzymes, eventually leading to oxidative stress condition.

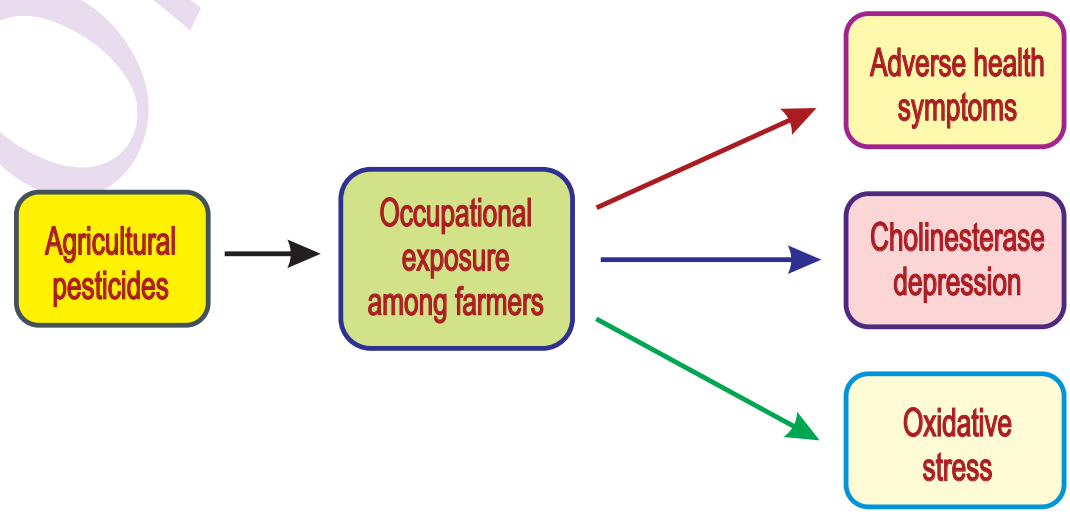




\section{Introduction}

India is an agricultural country and pesticides are indiscriminately used for agricultural practices by farm workers in crop fields. India ranks $2^{\text {nd }}$ in Asia and $12^{\text {th }}$ globally in terms of annual pesticide consumption (Bhardwaj and Sharma, 2013). Unsafe methods of handling and spraying pesticides by farm workers in agricultural fields in India have led to occupational exposure to pesticides, which can cause hazardous health effects. In developing countries like India, pesticide sprayers do not use Personal Protective Equipments (PPE) like safety masks, gloves, aprons etc., during spraying activities which result in their body exposure to pesticides via inhalation, ingestion and dermal absorption (Fareed et al., 2013, Gupta, 2004).

Organophosphate pesticides inhibit the action of acetylcholinesterase which is an enzyme used to deactivate the nerve transmitter acetylcholine at nerve endings, thus Organophosphate pesticides increases the cholinergic effects of neurotransmitter, acetylcholine in the body and depolarization of neural transmission (Weiss et al., 2004). Acetylcholinesterase activity (AChE) in the red blood cells and butyrylcholinesterase activity (BChE) in plasma have been used to monitor the extent of Organophosphate pesticides and carbamate exposure (Mekonnen and Ejigu, 2005). Gomes et al. (1997) observed inhibited AChE activity among the farm workers exposed to Organophosphate pesticides and carbamate pesticides. Decreased cholinesterase activity was observed among the farm workers who handled Organophosphate pesticides and carbamates (McConnell and Magnotti, 1994). Inhibited activity of BChE due to Organophosphate pesticides exposure was also observed among pesticides sprayers in India (Rastogi et al., 2008). Both AChE and BChE level in blood is considered as important biomarkers for the extent of exposure to organophosphate and carbamate pesticides.

Oxidative stress plays an important role in toxicity of various pesticides including, synthetic pyrethroid, organochlorine and carbamate pesticides (Stevenson et al., 1995). A balance between the production of free radicals and antioxidant defenses in the body has important health implications (Harman et al., 1999). Pesticides may induce oxidative stress, leading to generation of free radicals and alteration in antioxidants, oxygen free radicals, the scavenging enzyme system, and lipid peroxidation (Banerjee et al., 1999; Ahmed et al., 2000; Banerjee et al., 2001; Ranjbar et al., 2002; Kesavachandran et al., 2006; Singh et al., 2007). Earlier studies have demonstrated oxidative stress induced by organophosphate pesticides in humans (Banerjee et al., 2001; Ranjbar et al., 2002).

Our research group previously reported respiratory health problems and alterations in hematological profile among pesticide sprayers who were exposed to organophosphate pesticides pesticides in rural agricultural sector of Lucknow district in India (Fareed et al., 2013). The aim of the present study was to explore cholinesterase depression and oxidative stress among the farm workers who are exposed to pesticides.

\section{Materials and Methods}

Study design : This is a comparative cross sectional study design which was conducted at Malihabad and Bakshi Ka Talab regions of Lucknow district located in North India. These areas have several mango plantations where agricultural workers spray pesticides to protect the mango crop from harmful pests thereby, enhancing the mango crop productivity. These agricultural workers have experience of spraying pesticides in mango plantation from 1-30 years. Spraying operations last for 2 to 8 hour / week per season on the trees of mango orchards from December to March every year. Mixing of chemicals with bare hands and leakage from tanks of pesticide during spraying operations were found to be common. Sprayers of mango plantations were using organophosphate pesticides (monocrotphos, dichlorvos, malathion, methyl parathion), organochlorines (endosulfan, thiodon), pyrethroids (cypermethrin) and carbamates (carbaryl).

Subjects : The subjects were selected on the basis of the results of a preliminary questionnaire specifically designed for the study. All the subjects were engaged in spraying of agricultural pesticides without using any PPE. Fifty two male pesticide sprayers, who reported some chronic and acute health symptoms for different organ systems, were selected. The study was compared with 30 healthy males, having no previous or current occupational exposure to pesticides, taken as control from nearby areas with same socio-economic status. On the basis of area of living, ethnicity of both groups of subjects was almost similar. The purpose of the study was explained to all the participants and their consent was obtained. All the health surveys and collection of blood samples of pesticide sprayers were performed during the end phase of pesticide application season in the month of March with time interval of 1-2 days after the last spraying operation.

Pesticide sprayers were selected on the basis of inclusion and exclusion criteria.

Inclusion criteria of pesticide sprayers (exposed subjects) included : Male pesticide sprayers with age group of 18-60 yrs; Pesticide sprayers must have at least six months previous experience in spraying operations in field; Pesticide sprayers having minimum 2 chronic or acute health symptoms for any organ system.

Inclusion criteria of control subjects include healthy male resident who did not handle pesticides and having similar socio economic status and age group of exposed subjects.

Questionnaire : A preliminary structured questionnaire was 
designed to record the personal and occupational information along with pesticide exposure and health status of the pesticide sprayers. Each pesticide sprayer was interviewed based on questionnaire like general information about the name, age, smoking habit of individual pesticide sprayer; work practices of pesticide sprayers such as use of PPE, hygienic practices during loading and unloading processes were recorded.

Clinical examination : Clinical examination for adverse health effects was done by a medical expert and the symptoms for chronic or acute illness were recorded for every pesticide sprayer who participated in the study. The clinical examination comprised of medical history, general physical examination and detailed examination of different organ systems viz. nervous, respiratory, cardiovascular, gastro-intestinal, ocular, dermal and musculoskeletal. Signs and symptoms observed for each subject were entered in the questionnaire.

Ethical issues : Human ethical clearance was obtained from "Human Ethics Committee" of Indian Institute of Toxicology Research for collecting blood samples and clinical investigations of the participants. All the participants provided their written informed consent to participate in the study, which was approved by Institutional Human Ethics Committee. All the documents including questionnaires and consent forms of all the participants were safely kept for data analysis.

Blood sample collection : Approximately $3.0 \mathrm{ml}$ of venous blood was collected in the heparinised glass vials as coded samples from both the control and sprayers. Samples were transported to the Laboratory of Epidemiology Division of Indian Institute of Toxicology Research, Lucknow, India in ice-cold condition immediately after collection. Investigation of biochemical parameters for oxidative stress and cholinesterase estimation were carried out on same day of blood collection.

Estimation of cholinesterase activity : Blood AChE and BChE activities were assayed by the method of by Ellman et al. (1961) as modified by Chambers and Chambers, (1989) by taking acetylthiocholine iodide and butyrylthiocholine iodide respectively as substrate and expressed as mmols hydrolyzed $\mathrm{h}^{-1}$ $\mathrm{I}^{-1}$ blood $\left(\mathrm{IUI}^{-1}\right)$. The AChE and BChE activities were measured as a biomarker of organophosphate pesticides and carbamate pesticides exposure among study subjects.

Estimation of oxidative stress parameters : Catalase (CAT) activity in the hemolysate was determined by the method of Sinha (1972) using $\mathrm{H}_{2} \mathrm{O}_{2}$ as substrate and expressed as $\mu \mathrm{mol} \mathrm{H}_{2} \mathrm{O}_{2}$ decomposed min $^{-1} \mathrm{~g}^{-1} \mathrm{Hb}$. Glutathione peroxidase (GPx) activity in the hemolysate was assayed using $\mathrm{H}_{2} \mathrm{O}_{2}$ as substrate in the presence of Glutathione (GSH) following the method of Rotruck et al. (1973) and expressed as mol GSH oxidized $\min ^{-1} \mathrm{~g}^{-1} \mathrm{Hb}$. Hemoglobin content in the hemolysate was measured by the method of Drabkin and Austin (1932). The extent of lipid peroxidation in the whole blood was assayed by measuring the formation of malondialdehyde (MDA) content (Stocks and Dormandy, 1971), and expressed as nmol MDA formed per $\mathrm{ml}$ of blood using a molar extinction coefficient of $1.56 \times 105 \mathrm{M}^{-1} \mathrm{~cm}^{-1}$. Reduced GSH was estimated in the whole blood (Kuo et al., 1983) and expressed as $\mu \mathrm{mol} \mathrm{ml}{ }^{-1}$ blood.

Statistical analysis : Descriptive statistics were generated for demographic parameters in the control group and pesticide sprayers. Frequencies and percentages have been shown for all the categorical parameters. Unpaired student's t test was used to compare the mean values of the quantitative characteristics (demographic parameters, oxidative stress parameters and cholinesterase activity) between the control and exposed group. Chi square test was applied for comparing categorical outcomes (health symptoms). The criterion for significance was set at $p<$ 0.05. All the statistical analysis were performed using EPI INFO 7.1.1.0 software (Centre for Disease Control and Prevention, Georgia, USA) and IBM SPSS Statistics version 20.

\section{Results and Discussion}

Mean age of pesticide sprayers was $37.99 \pm 15.34$ (range: 18 - 55) years; mean height of pesticide sprayers was $163.64 \pm$ 6.33 (range: 155 - 170) cms; mean weight of pesticide sprayers was $51.87 \pm 8.34$ (range: $46-67$ ) kgs; mean BMl of pesticide sprayers was $19.28 \pm 2.68$ (range: $18-23$ ) $\mathrm{kg} \mathrm{m}^{-2}$; mean exposure of pesticides among sprayers was $14.08 \pm 10.51$ (range: 1 - 20) years, respectively.

Table 1 shows information about different agricultural work practices followed by pesticide sprayers which are based on preliminary questionnaire designed for this study. Information about the place of pesticide storage, place for pesticide preparation and handling, personal protecting equipment and awareness during mixing/loading/spraying, fate of empty packages/containers of pesticide is shown in Table 1.

Self reported health symptoms observed among pesticide sprayers (Table 2) were related to different organ systems viz. nervous (48.95\%), ocular $(35.15 \%)$, respiratory (38.49\%), cardio vascular $(40.58 \%)$, gastro-intestinal $(37.66 \%)$, musculo-skeletal $(58.58 \%)$ and dermal $(9.62 \%)$. These symptoms among pesticide sprayers were significant as compared to control subjects.

The biomarkers of organophosphate pesticides and carbamate pesticides exposure viz., acetylcholinesterase and butyrylcholinesterase activity in blood among pesticide sprayers were analysed and the results are shown in Table 3. Activities of both acetylcholinesterase and butyrylcholinesterase were found to be significantly depressed $(p<0.05)$ among the pesticide sprayers as compared to control subjects.

The oxidative stress parameters viz. catalase, 
Table 1: Information about the agricultural work practices followed by pesticide sprayers

\begin{tabular}{|c|c|c|c|}
\hline \multicolumn{2}{|l|}{ Variables } & \multicolumn{2}{|c|}{ Pesticide sprayers ( $\mathrm{N}=52) \mathrm{n}(\%)$} \\
\hline \multicolumn{4}{|c|}{ Place for pesticide storage } \\
\hline \multicolumn{2}{|l|}{ Inside the house } & \multicolumn{2}{|c|}{$24(46.15)$} \\
\hline \multicolumn{2}{|l|}{ Inside plantation areas } & \multicolumn{2}{|c|}{$5(9.6)$} \\
\hline \multicolumn{2}{|l|}{ No storage } & \multicolumn{2}{|c|}{$8(15.38)$} \\
\hline \multicolumn{2}{|c|}{ Tools storage room } & \multicolumn{2}{|c|}{$15(28.84)$} \\
\hline \multicolumn{4}{|c|}{ Place for pesticide preparation and handling } \\
\hline \multicolumn{2}{|c|}{ In home } & \multicolumn{2}{|c|}{$10(19.23)$} \\
\hline \multicolumn{2}{|l|}{ In fields } & \multicolumn{2}{|c|}{$24(46.15)$} \\
\hline \multicolumn{2}{|c|}{ Near pond } & \multicolumn{2}{|c|}{$21(40.38)$} \\
\hline \multicolumn{2}{|c|}{ Handling of pesticide container by bare hands } & \multicolumn{2}{|c|}{$52(100)$} \\
\hline \multicolumn{2}{|c|}{ Mixing of pesticide by bare hands } & \multicolumn{2}{|c|}{$17(32.69)$} \\
\hline \multicolumn{2}{|c|}{ Mixing of pesticide by rod } & \multicolumn{2}{|c|}{$6(11.04)$} \\
\hline \multicolumn{2}{|l|}{ Mixing by motor } & \multicolumn{2}{|c|}{$31(59.61)$} \\
\hline \multirow{2}{*}{\multicolumn{4}{|c|}{ Personal protecting equipment and awareness during mixing/loading/spraying }} \\
\hline & Use of gloves/goggles/apron & \multicolumn{2}{|c|}{0} \\
\hline Cloths wet during spraying & & & $9.23)$ \\
\hline Smoke while spraying & & & $6.92)$ \\
\hline Eat in the break between s & raying & & 4.23) \\
\hline Take bath after the end of s & raying & & 4.61) \\
\hline Change clothes at the end & fwork shift & & $0.76)$ \\
\hline Wash contaminated clothe & with family clothes & & $9.23)$ \\
\hline Any integrated pest mana & ement training taken & & \\
\hline Fate of empty packages & ontainers of pesticide & & \\
\hline Buried / burned & & & \\
\hline Discarded near the river/c & nal/field & & 7.30) \\
\hline Use athome & & & $1.15)$ \\
\hline Sold to scrap dealer & & & \\
\hline Used for some other work & & & \\
\hline Organ systems & Reported symptoms & $\begin{array}{l}\text { Control subjects } \\
(n=30) n(\%)\end{array}$ & $\begin{array}{l}\text { No. of pesticide sprayers } \\
(\mathrm{N}=52) \mathrm{n}(\%)\end{array}$ \\
\hline Nervous System & dizziness, headache and convulsions & $1(3.33)$ & $25(48.95)^{*}$ \\
\hline Ocular System & $\begin{array}{l}\text { Blurred vision, refractive error, watering of eyes, pain in eyes, } \\
\text { red swollen eyes, itching and burning sensation in eyes }\end{array}$ & $0(0)$ & $18(35.15)^{*}$ \\
\hline Respiratory System & Dry cough, productive cough and wheezing & $0(0)$ & $20(38.49)^{*}$ \\
\hline Cardio vascular System & Pain in chest, tachycardia and hypertension & $2(6.66)$ & $21(40.58)^{*}$ \\
\hline Gastro intestinal System & Hyperacidity, pain in abdomen and constipation & $2(6.66)$ & $19(37.66)^{*}$ \\
\hline Musculo skeletal System & Stiffness in joints and muscles, body ache, weakness in limbs & $0(0)$ & $30(58.58)^{*}$ \\
\hline Dermal System & Burning sensation of skin and itching & $0(0)$ & $5(9.62)^{*}$ \\
\hline
\end{tabular}

${ }^{*} p<0.05$

glutathione peroxidase, glutathione and malondialdehyde for extent of lipid peroxidation among the pesticide sprayers with adverse health symptoms were analyzed (Table 4). Activity of blood catalase enzyme $\left(x 10^{4} \mu \mathrm{mol} \mathrm{H}_{2} \mathrm{O}_{2}\right.$ decomposed $\left.\min ^{-1} \mathrm{~g}^{-1} \mathrm{Hb}\right)$ was found to be higher in pesticide sprayers as compared to control subjects, but were not found to be statistically significant. Activity of blood glutathione peroxidase enzyme ( $\mu \mathrm{mol} \mathrm{GSH}$ oxidized $\min ^{-1} \mathrm{~g}^{-1} \mathrm{Hb}$ ) was found to be significantly higher $(\mathrm{p}<0.05)$ in pesticide sprayers as compared to control subjects. Blood

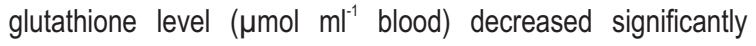

$(p<0.05)$ in pesticide sprayers as compared to control subjects. Blood malondialdehyde ( $\mathrm{nmol} \mathrm{ml}{ }^{-1}$ blood) level, as an end product of lipid peroxidation was found to be more in pesticide sprayers as compared to control subjects, but was found to be statistically in significant.

Correlation between different oxidative stress parameters and cholinesterase activity for both AChE and BChE are shown in Table 5. There was significant negative correlation of AChE with CAT, GPx and MDA $(p<0.01)$ and positive significant correlation between AChE and GSH $(p<0.01)$. There was also 
Table 3: Cholinesterase activity (IUL $\left.L^{-1}\right)$ in study subjects

\begin{tabular}{lll}
\hline Cholinesterase activity $\left(\mathrm{IUL}^{-1}\right)$ & Control subjects(n=30)Mean \pm SD & Pesticide sprayers $(\mathrm{n}=\mathbf{5 2})$ Mean \pm SD \\
\hline Acetylcholinesterase & $559.38 \pm 296.41$ & $411.95 \pm 218.73^{*}$ \\
Butyrylcholinesterase & $414.79 \pm 178.92$ & $270.97 \pm 193.07^{*}$ \\
\hline
\end{tabular}

${ }^{*} p<0.05$

Table 4 : Parameters for oxidative stress among study subjects

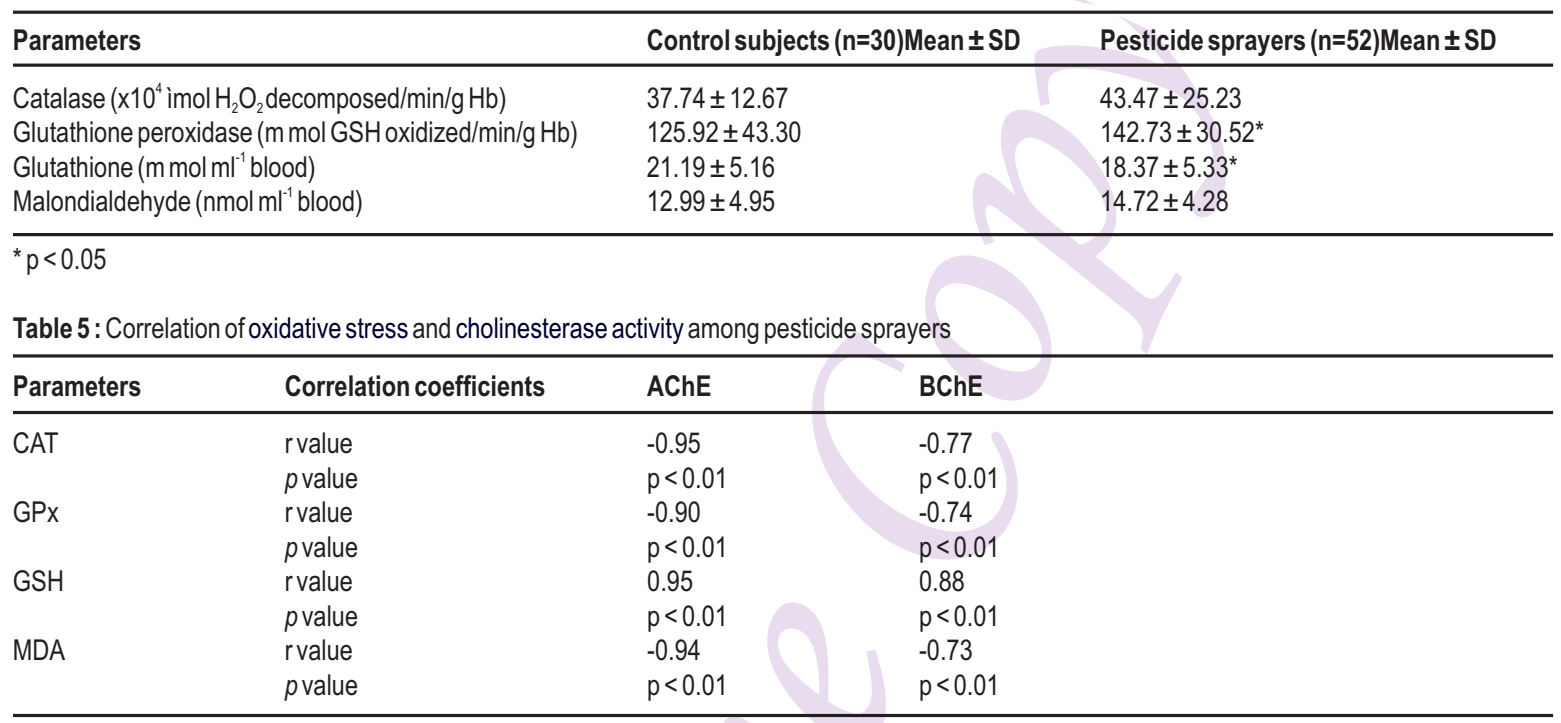

significant negative correlation of BChE with CAT, GPx and MDA $(p<0.01)$ and significant positive correlation between $B C h E$ and $\mathrm{GSH}(\mathrm{p}<0.01)$, respectively.

The present study shows that due to unsafe work practices like not using PPEs, the pesticides sprayers were exposed to pesticides which might lead to different health risks. Mixing of chemicals with bare hands, leakages from tanks of pesticide during spraying operations was common. Pesticide sprayers did not use any personal protective equipments during spraying operations. The exposure of the subjects can be through breathing since no face masks were used by the sprayers at work place. Sprayers used to eat food or drink water during spraying operation without washing hands thereby, consuming food contaminated with pesticides which was another route for exposure. Since proper protective clothes were not worn by sprayers at work place, hence they were also exposed via dermal route.

Clinical examination showed illness for nervous system, ocular system, respiratory system, gastro-intestinal system, musculo-skeletal system and dermal system among the pesticide sprayers which clearly depicts the adverse health effects among the pesticide sprayers due to occupational exposure of agricultural pesticides. Earlier, in a study carried out south India, the signs and symptoms of illnesses due to exposure to pesticides among farmers were assessed and farmers reported acute signs and symptoms of excessive sweating, burning/ stinging/itching of eyes, dry/sore throat, excessive salivation (Chitra et al., 2006) which were also found in the present study. In an earlier study, green house workers exposed to pesticides in Turkey showed symptoms of fatigue, headache, changes in mood, irritation in the eye, blurring of vision, difficulty in breathing, pressure on the chest, coughing, mucous saliva, skin itch, scars, dizziness, depression, forgetfulness, memory disorders, sleeplessness nausea, vomiting, bleeding of nose and weight loss (Ergonen et al., 2005); similar type of symptoms were also reported in the present study. Clinical findings in this study support similar kind of studies on occupational exposure to pesticides among farm workers (Chitra et al., 2006; Kesavachandran et al., 2006, Ergonen et al., 2005, Ecobichon et al., 1996, Azmi et al., 2009).

Organophosphate pesticides and carbamate pesticides used by the pesticide sprayers in the present study are neurotoxic in nature. The evidence of organophosphate pesticides toxicity was observed from depeleted AChE (RBC cholinesterase) and $\mathrm{BChE}$ (Plasma cholinesterase) in the blood of pesticide sprayers. Exposure to large doses of organophosphate pesticides is required for significant AChE inhibition to occur (He et al., 1999). 
Results of the present study related to inhibition in cholinesterase activity among pesticide exposed farm workers are in agreement with the previous studies (Gomes et al., 1997; Lopez-Carillo and Lopez-Cervantes, 1993; Coye et al., 1986; McConnell et al., 1992, Rastogi et al., 2008).

Oxidative stress plays an important role in the toxicity of various pesticides including organophosphate pesticides, synthetic pyrethroid, organochlorine and carbamate pesticides (Stevenson et al., 1995). In the present study, high activity of blood CAT and GPx; low level of blood GSH and high level of blood MDA (increased lipid peroxidation) were found, which was evident as sub-clinical state of oxidative stress among the pesticide sprayers. CAT, GPx, GSH and LPO were found to be significantly correlated with $\mathrm{AChE}$ and BChE which shows that oxidative stress was found to be more among those subjects in which AChE and BChE activities were depressed, which shows that organophosphate pesticides pesticide exposure causing oxidative stress since depressed activity of AChE and BChE is implicated to organophosphate pesticides pesticide exposure. There is evidence that sub-chronic exposure to malathion increased malondialdehyde (MDA) content and decreased reduced form of glutathione (GSH) levels; and depressed activities of catalase, glutathione peroxidase, glutathione reductase and glutathione $S$-transferase in the blood, suggesting that organophosphate pesticides may induce oxidative stress leading to generation of free radicals and alteration in antioxidants or oxidized free radicals scavenging enzymes (Ahmed et al., 2000). This study demonstrated oxidative stress among the pesticides sprayers with depressed AChE activity, however another study (Shadnia et al., 2005) showed no difference in LPO and AChE activity among study group exposed to organophosphate pesticides. Some previous similar kind of studies support the findings of this study related to oxidative stress (Singh et al., 2007, Prakasam et al. 2001, Ogut et al. 2011, Akhgari et al., 2003, Ranjbar et al., 2002). Increased activity of GPx in the present study could be due to significant production of $\mathrm{H}_{2} \mathrm{O}_{2}$ in pesticide-induced toxicity (Samanta and Chainy, 1997). In previous study, glutathione levels were depressed by organophosphate pesticides pesticide exposure through a process that results in activation of more reactive oxygen species leading to enhanced lipid peroxidation (Abdollahi et al., 2004).

Present study shows that pesticide sprayers are at higher risk to acquire toxic effects due to unsafe occupational work practices. The study concludes that occupational exposure to pesticides leads to cholinesterase depression and alteration in anti-oxidant enzymes, eventually leading to oxidative stress condition.

\section{Acknowledgments}

Financial assistance for this research project and Senior Research Fellowship to one of the author Mohammad Fareed was sanctioned by Council of Scientific and Industrial Research, New Delhi, India which is highly appreciated and acknowledged by the authors. The authors also acknowledge the Director, CSIRIndian Institute of Toxicology Research, Lucknow for his encouragement and providing all the necessary facilities required for this study.

\section{References}

Abdollahi, M., A. Ranjbar, S. Shadnia, S. Nikfar and A. Rezaie: Pesticides and oxidative stress: A review. Med. Sci. Monit., 10, 141-147 (2004).

Ahmed, R.S., V. Seth, S.T. Pasha and B.D. Banerjee: Influence of dietary ginger (Zingiber officinales Rosc) on oxidative stress induced by malathion in rats. Food Chem. Toxicol., 38, 443-450 (2000).

Akhgari, M., M. Abdollahi and A. Kebryaeezadeh: Biochemical evidence for free radical-induced lipid peroxidation as a mechanism for subchronic toxicity of malathion in blood and liver of rats. Hum. Exper. Toxicol., 22, 205-211 (2003).

Azmi, M.A., S.N. Naqvi, K. Akhtar, Moinuddin, S. Parveen, R. Parveen and M. Aslam: Effect of pesticide residues on health and blood parameters of farm workers from rural Gadap, Karachi, Pakistan. J. Environ. Biol., 30, 747-756 (2009).

Banerjee, B.D., V. Seth and R.S. Ahmed: Pesticide-induced oxidative stress: Perspectives and trends. Rev. Environ. Hlth., 16, 1-40 (2001).

Banerjee, B.D., V. Seth, A. Bhattacharya, S.T. Pasha and A.K. Chakraborty: Biochemical effects of some pesticides on lipid peroxidation and free radical scavengers. Toxicol. Lett., 107, 33-47 (1999).

Bhardwaj, T. and J.P. Sharma: Impact of pesticides application in agricultural industry: An Indian Scenario. Inter. J. Agric. Food Sci. Technol., 4, 817-822 (2013).

Chambers, J.E. and H.W. Chambers: An investigation of acetylcholinesterase inhibition and aging and choline acetyltransferase activity following a high level acute exposure to paraoxon. Pest. Biochem. Physiol., 33, 125-131 (1989).

Chitra, G.A., V.R. Muraleedharan, T. Swaminathan and D. Veeraraghavan: Use of pesticides and its impact on health of farmers in South India. Inter. J. Occup. Environ. Hlth., 12, 228-233 (2006).

Coye, M.J., J.A. Lowe and K.T. Maddy: Biological monitoring of agricultural workers exposed to pesticides: Cholinesterase activity determination. J. Occup. Med., 28, 619-627 (1986).

Drabkin, D.L. and J.H. Austin: Spectrophotometric studies: Spectrophotometric constant for common hemoglobin derivatives in human, dog and rabbit blood. J. Biol. Chemi., 98, 719 (1932).

Ecobichon, D.J.: Toxic effects of pesticides. In: Casarett and Doull's Toxicology: The Basic Science of Poisons (Eds.: C.D. Klaassen and J. Doull). $5^{\text {th }}$ Edn., New York, MacMillan, pp. 643-689 (1996).

Ellman, G.L., K.D. Curtney, V. Andrews and R.M. Featherstone: A new and rapid colorimetric determination of acetyl cholinesterase activity. Biochem. Pharmacol., 7, 88-95 (1961).

Ergonen, A.T., S. Salacin and M.H. Ozdemir: Pesticide use among greenhouse workers in Turkey. J. Clini. Foren. Medi., 12, 205-208 (2005).

Fareed, M., M.K. Pathak, V. Bihari, R. Kamal, A.K. Srivastava and C.N. Kesavachandran: Adverse respiratory health and hematological alterations among agricultural workers occupationally exposed to 
organophosphate pesticides: A cross-sectional study in North India. Plos One, 8, e69755. doi:10.1371/journal.-pone.0069755 (2013).

Gomes, J., O. Lioyd, D.M.F. Revitt and J.N. Norman: Erythrocyte cholinesterase activity levels in desert farm workers. Occupational Medicine, 47, 90-94 (1997)

Gupta P.K.: Pesticide exposure-Indian scene. Toxicology, 198, 83-90 (2004).

Harman, D.: Aging and oxidative stress. J. Inter. Feder. Clinical Chem., 10, 24-47 (1999).

He, F.: Biological monitoring of exposure to pesticides: Current issues. Toxicology Letters, 108, 277-283 (1999).

Kesavachandran, C.N., S.K. Rastogi, N. Mathur, M.K.J. Siddiqui, V.K. Singh, V. Bihari and R.S. Bharti: Health status among pesticide applicators at a mango plantation in India. J. Pest. Saf. Educ., 8, 19 (2006).

Kesavachandran, C.N., V.K. Singh, N. Mathur, S.K. Rastogi, M.K.J. Siddiqui, M.M.K. Reddy, R.S. Bharti and A.M. Khan: Possible mechanism of pesticide toxicity-related oxidative stress leading to airway narrowing. Redox Report, 11, 1-4 (2006).

Kuo, C.H., K. Maita, S.D. Sleight and J.B. Hook: Lipid Peroxidation: A possible mechanism of cephaloridine- induced nephrotoxicity. Toxicol. App. Pharmacol., 67, 78-88 (1983).

Lopez-Carillo, L. and M. Lopez-Cervantes: Effects of exposure to organophosphates on serum cholinsterase levels. Arch. Environ. Hlth, 48, 359-363 (1993).

McConnell, R., M. Gordon, D.L. Murray and R. Magnotti: Hazards of closed pesticide mixing and loading systems- the paradox of protective technology in the third world. British J. Indu. Med., 49, 615-619 (1992).

McConnell, R. and R. Magnotti: Screening for insecticide overexposure under field conditions- A re-evaluation of the tintimetric cholinesterase kit. Amer. J. Public Hlth., 84, 479-481 (1994).

Mekonnen, Y. and D. Ejigu: Plasma cholinesterase level of Ethiopian farm workers exposed to chemical pesticide. Occup. Medi., 55, 504-505 (2005).

Ogut, S., F. Gultekin, A.N. Kisioglu and E. Kucukoner: Oxidative stress in the blood of farm workers following intensive pesticide exposure. Toxicol. Ind. Hlth., 27, 820-825(2011).

Prakasam, A., S. Sethupathy and S. Lalitha: Plasma and RBCs antioxidant status in occupational male pesticide sprayers. Clinica ChimicaActa, 310, 107-112 (2001).

Ranjbar, A., P. Pasalar and M. Abdollahi: Induction of oxidative stress and acetylcholinesterase inhibition in organophosphorous pesticide manufacturing workers. Hum. Experim. Toxicol., 21, 179-182 (2002).

Rastogi, S.K., V.K. Singh, C. Kesavachandran, Jyoti, M.K.J. Siddiqui, N. Mathur and R.S. Bharti: Monitoring of plasma butyrylcholinesterase activity and haematological parameters in pesticide sprayers. Ind. J. Occupat. Environ. Medi., 12, 29-32 (2008).

Rotruck, J.T., A.L. Pope, H.E. Ganther, A.B. Swanson, D.G. Hofeman and W.C. Hoekstra: Selenium: Biochemical role as a component of glutathione peroxidase. Science, 179, 588-590 (1973).

Samanta, L. and G.B. Chainy: Comparison of hexachlorocyclohexaneinduced oxidative stress in the testis of immature and adult rats. Comp. Biochem. Physiol. Pharmacol. Toxicol. Endocrinol., 118, 319-327 (1997).

Shadnia, S., E. Azizi and R. Hosseini: Evaluation of oxidative stress and genotoxicity in organophosphorus insecticide formulators. Human Exp.Toxicol., 24, 439-445(2005).

Singh, V.K., Jyoti, M.M.K. Reddy, C.N. Kesavachandran, S.K. Rastogi and M.K.J. Siddiqui: Biomonitoring of organochlorines, glutathione, lipid peroxidation and cholinesterase activity among pesticide sprayers in mango orchards. Clinica Chimica Acta, 377 , 268-272 (2007)

Sinha, A. K.: Colorimetric assay of Catalase. Analytical Biochemistry, 47, 389-394 (1972).

Stevenson, D.E., J.P. Kehrer, K.L. Kolaja, E.F. Walborg and J.E. Klaunig: Effect of dietary antioxidants on dieldrin-induced hepato-toxicity in mice. Toxicology Letters, 75, 177-183(1995).

Stocks, J. and T.L. Dormandy: Auto oxidation of red lipids induced by hydrogen peroxide. Brit. J. Hematol., 20, 95-111 (1971).

Weiss, B., S. Amler and R.W. Amler: Pesticides. Pediatrics, 113, 10301037 (2004). 